\title{
Myocardial perfusion scintigraphy before and after cardioversion for atrial fibrillation: Recovery of quantitative parameters
}

\author{
Daphne D. D. Rietbergen, MD, a Arthur J. H. A. Scholte, MD, PhD, \\ Imad Al Younis, MD, and Marcel P. M. Stokkel, $M D, P^{c}{ }^{c}$
}

Case presentation. A 54-year-old woman with a history of paroxysmal atrial fibrillation (AF) was referred to our department for myocardial perfusion scintigraphy (MPS) due to suspicion of coronary artery disease. The history revealed several cardioversions and two ablation-procedures for the treatment of AF. Adenosine stress test was used because the $\beta$-blockade medication was not stopped before of the exercise test. Prior to the adenosine-stress MPS, the electrocardiogram showed AF with a ventricular rate of 120 beats/minute (bpm) (Figure 1). $712 \mathrm{MBq}{ }^{99 \mathrm{~m}} \mathrm{Tc}$-tetrofosmin was administrated at the third minute during adenosine infusion $(140 \mu \mathrm{g} / \mathrm{kg}$ body weight/minute for $6 \mathrm{~min}$ with simultaneous handgrip exercise). During adenosine infusion the patient complained of palpitations; however, no hemodynamic changes and no progression of the initial significant ST-T segment changes were observed. Immediately after acquisition of the images the patient underwent electric cardioversion and was discharged from the hospital the same day with sinus rhythm. Three days later the patient underwent rest MPS during sinus rhythm (60 bpm) (Figure 2). $768 \mathrm{MBq}{ }^{99 m}$ Tc-tetrofosmin was injected and $45 \mathrm{~min}$ later rest-images were acquired. Gated myocardial perfusion stress- and rest-images were acquired using a

From the Departments of Nuclear Medicine, ${ }^{\mathrm{a}}$ and Cardiology ${ }^{\mathrm{b}}$ Leiden University Medical Center, Leiden, The Netherlands; and Department of Nuclear Medicine, ${ }^{c}$ Antoni van Leeuwenhoekhospital, Amsterdam, The Netherlands.

Reprint requests: Imad Al Younis, MD, Department of Nuclear Medicine, Leiden University Medical Center, P.O. Box 9600, 2300 RC Leiden, The Netherlands; I.al_Younis@lumc.nl.

J Nucl Cardiol 2011;18:192-5.

$1071-3581 / \$ 34.00$

Copyright (c) 2010 The Author(s). This article is published with open access at Springerlink.com

doi:10.1007/s12350-010-9299-y three-headed Gamma Camera (GCA-9300, Toshiba, Japan) and analyzed using the 4DM-software (Corridor 4DM, INVIA, Ann Arbor, University of Michigan Medical Center).

Perfusion images (both stress and rest) showed slightly decreased tracer uptake anteroseptal due to breast attenuation, but no other abnormalities were observed. The left ventricular ejection fraction (LVEF) was $56 \%$ during adenosine-stress and $58 \%$ at rest. The left ventricular volumes during adenosine-stress were $86 \mathrm{ml}$ (left ventricular end-diastolic, LVED) and $38 \mathrm{ml}$ (left ventricular end-systolic, LVES), but significantly increased at rest to 137 and $58 \mathrm{ml}$, respectively (Figure 3). Nine months later, a second MPS at rest was performed during sinus rhythm $(55 \mathrm{bpm})$ to evaluate the functional parameters and volumes. In the time between the two rest MPS studies, the patient did not have any cardioversion or other cardiac intervention. The second MPS study at rest (sinus rhythm) showed a LVEF of $67 \%$ with LVED volume of $133 \mathrm{ml}$ and LVES volume of $44 \mathrm{ml}$. The perfusion images did not show any significant changes. The changes in left ventricular volumes between the 3 MPS acquisitions are displayed in Figure 4.

Discussion. AF is the most common arrhythmia and occurs in $0.4 \%$ of the general population. Furthermore, the incidence and prevalence increase with the age. ${ }^{1}$ Cardioversion of AF is generally performed in an effort to improve cardiac function, to relieve symptoms and to decrease the incidence of thrombus formation. Although left ventricular dysfunction has been shown to improve after cardioversion, it can persist for a few weeks. $^{2}$ In this case, we present the effect of cardioversion on left ventricular volumes and ejection fraction shown by MPS.

The early and late effects of cardioversion on left ventricle volumes and function has been reported before, using cinematographic breath-hold magnetic resonance imaging and echocardiography. ${ }^{2-5}$ This report showed the short- and long-term effects of cardioversion on left ventricular function by MPS.

In this case, myocardial dysfunction is probably due to tachycardia with a ventricular rate of $120 \mathrm{bpm}$ at 


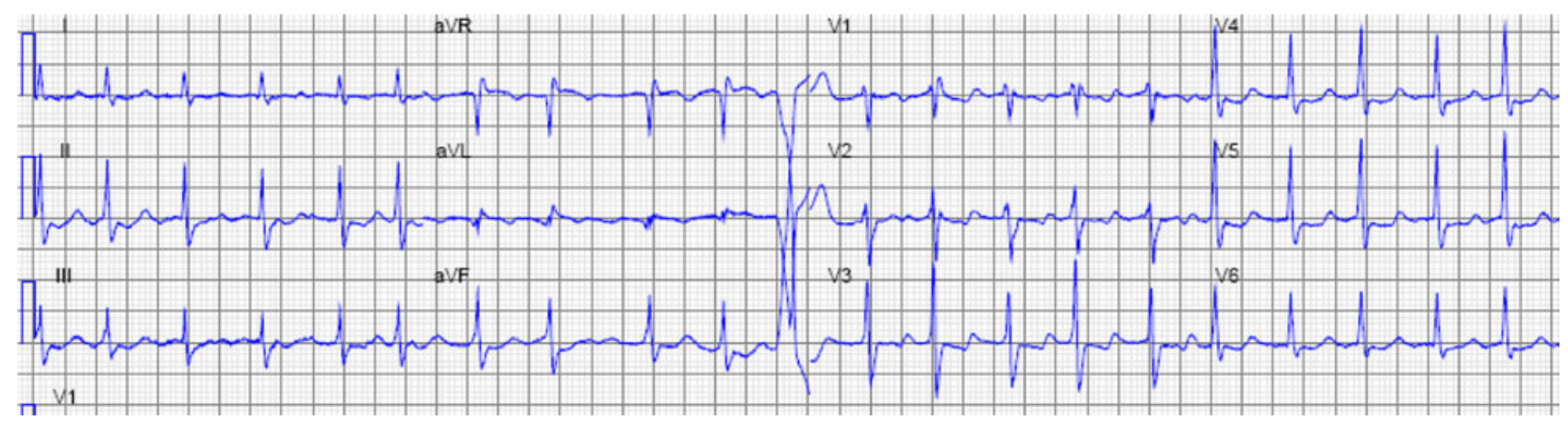

Figure 1. Baseline ECG showing atrial fibrillation with a ventricular rate of 120 beats/minutes, an incomplete right bundle branch block and slight diffuse ST-segment depression.

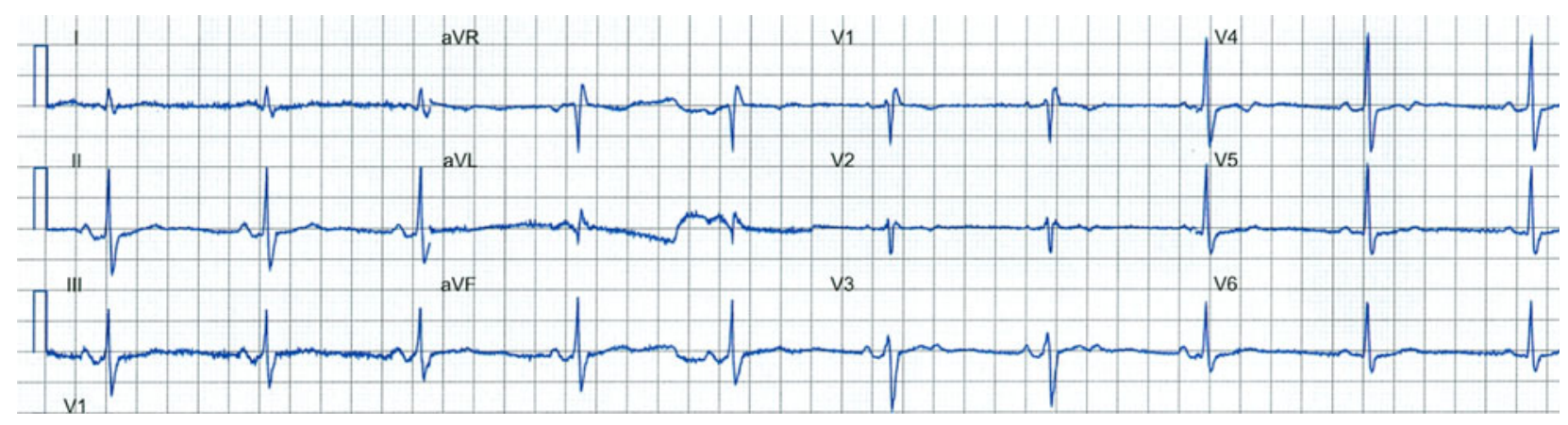

Figure 2. Rest ECG showing normal sinus rhythm with a heart rate of 60 beats/minutes and recovery of the ST-segment depression.

acquisition. During sinus rhythm improvement in LV volumes and a slightly (but not significant) increase in LVEF was observed 3 days after cardioversion. The significant increase in LVED volume can be explained by the regulation of the rhythm, increased cycle length and a reduction in heart rate after cardioversion. Nine months after cardioversion there was a significant increase in LVEF due to full recovery of the volumina with a further increase in stroke volume.

It has to be realized that there are some technical limitations related to the assessment of LV parameters by gated SPECT during AF. First, heart rate can influence EDV measurements. An increase in heart rate will ensure a smaller contribution of diastolic images to the entire summed volume, because the heart will remain a shorter period of time in diastole and may vary from beat to beat during AF. This may cause errors in accurate identification of the end-diastolic and end-systolic phases. The images are referred to as "systolic pattern" and tend to display a LV cavity that is smaller with contracted walls. In addition, a reduced heart rate will produce the opposite. Secondly, optimal image reconstruction is based on stable R-R interval. If $\mathrm{R}-\mathrm{R}$ intervals vary widely during acquisition, as is the case in $\mathrm{AF}$, temporal misregistration occurs and image quality is severely degraded. This effect can be lessened by computer algorithms using acceptance windowing. A high acceptance window will reveal poor image due to temporal misregistration. However, on the other hand, a too low acceptance window will reveal a large number of rejected beats during acquisition and also causing poor image quality. In our case, we used a $50 \%$ acceptance window at all acquisitions and no rejected beats were registered. 


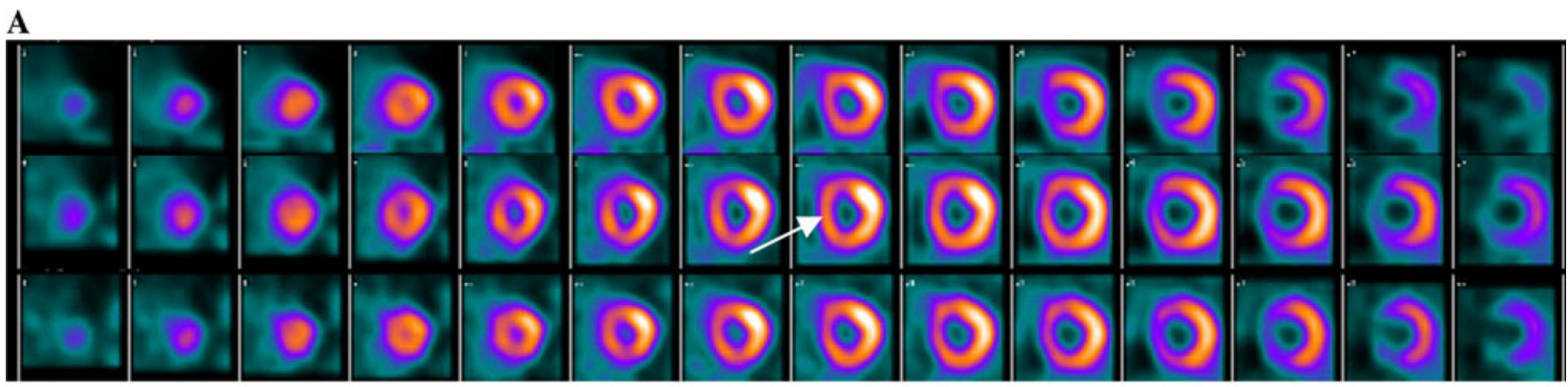

Adenosine

LVEF 56\%, ESV 38ml, EDV $86 \mathrm{ml}$

Rest 1

LVEF $58 \%$, ESV $58 \mathrm{ml}$, EDV $137 \mathrm{ml}$

Rest 2

LVEF $67 \%$, ESV 44ml, EDV $133 \mathrm{ml}$

B

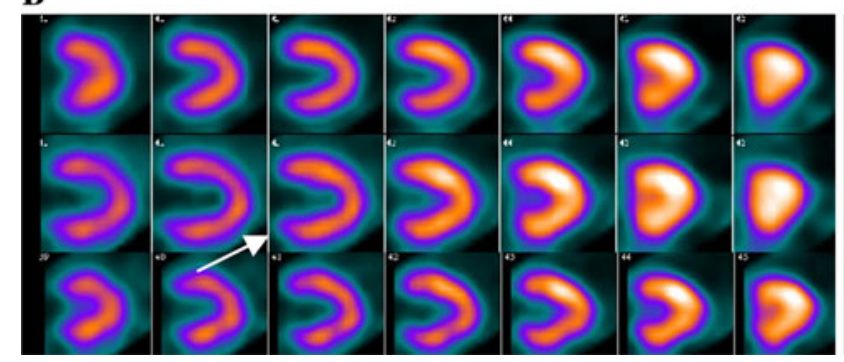

C

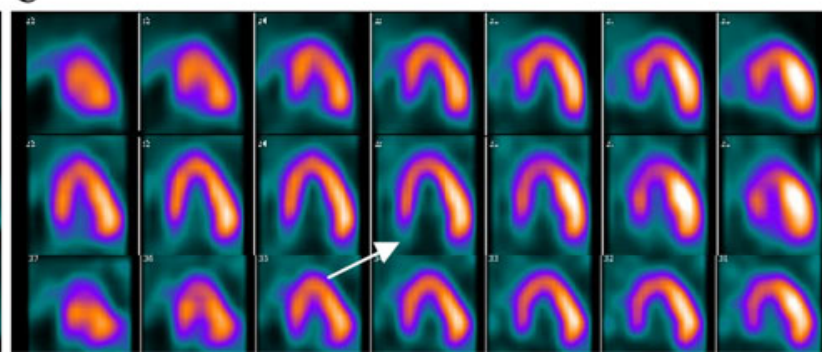

Figure 3. Short axis (A), vertical long axis (B), and horizontal long axis (C) of regional myocardial perfusion, stress images above, rest images below (rest 1: 3 days after stress MPS, rest 2: 9 months after stress MPS). An obvious increase of intracavitary LV volume (white arrow) and recovery of intracavitary LV volume is shown.

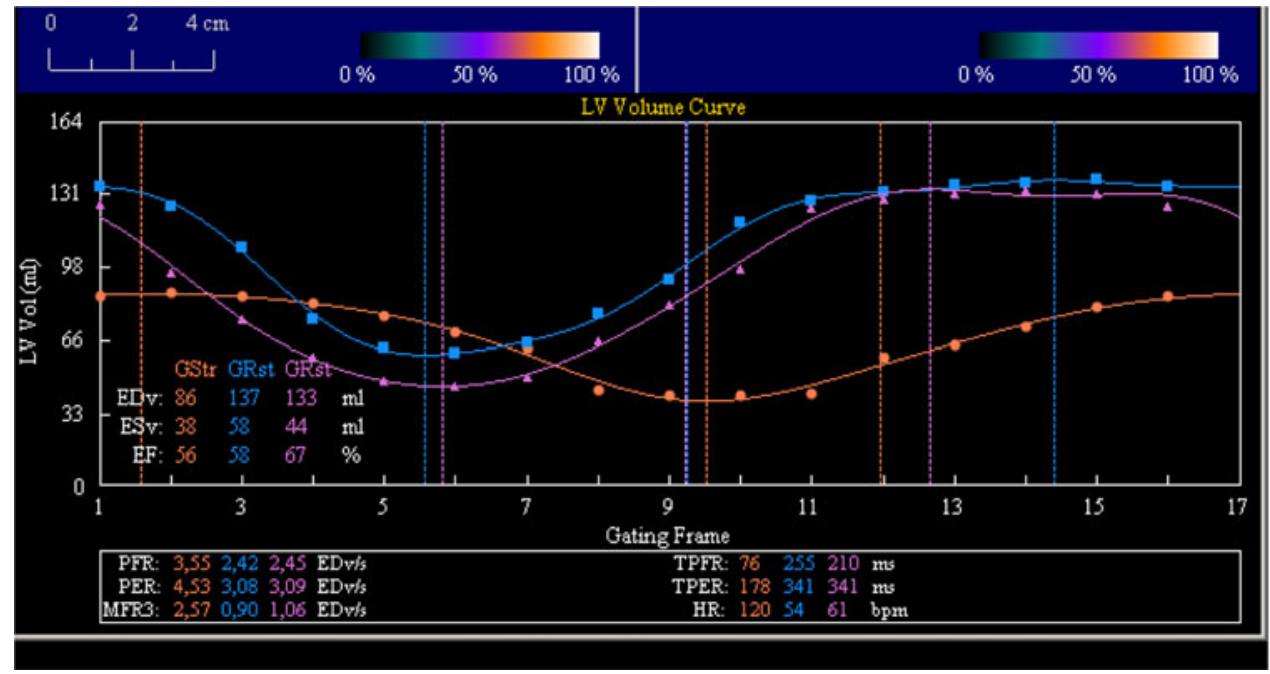

Red: Stress

Blue: Rest 1

Purple: Rest 2

Figure 4. Left ventricle volume curves. Red line stress acquisition. Blue line rest 1 (3 days after stress MPS) and purple line rest 2 (9 months after stress MPS) acquisition. A significant increase and recovery of LV volume is observed between the stress and rest 1 and 2 acquisition. 


\section{Open Access}

This article is distributed under the terms of the Creative Commons Attribution Noncommercial License which permits any noncommercial use, distribution, and reproduction in any medium, provided the original author(s) and source are credited.

\section{References}

1. Fuster V, Rydén LE, Cannom DS, Crijns HJ, Curtis AB, et al. ACC/ AHA/ESC 2006 guidelines for the management of patients with atrial fibrillation. Circulation 2006;114:e257-354.
2. Therkelsen SK, Groenning BA, Svendsen JH, Jensen GB. Atrial and ventricular volume and function evaluated by magnetic resonance imaging in patients with persistent atrial fibrillation before and after cardioversion. Am J Cardiol 2006;97:1213-9.

3. Raymond RJ, Lee AJ, Messineo FC, Manning WJ, Silverman DI. Cardiac performance early after cardioversion from atrial fibrillation. Am Heart J 1998;136:435-42.

4. Viswanathan K, Daniak S, Salomone K, Kiely T, Patel U, et al. Effect of cardioversion of atrial fibrillation on improvement in left ventricular performance. Am J Cardiol 2001;88:439-41.

5. Gopinathannair R, Sullivan R, Olshansky B. Tachycardia-mediated cardiomyopathy: Recognition and management. Curr Heart Fail Rep 2009;6:257-64. 